\title{
A NOVEL DE NOVO PARACENTRIC INVERSION [inv(20)(q13.1q13.3)] ACCOMPANIED BY AN 11q14.3-q21 MICRODELETION IN A PEDIATRIC PATIENT WITH AN INTELLECTUAL DISABILITY
}

\author{
Zachaki $\mathrm{S}^{1,2}$, Kouvidi $\mathrm{E}^{1}$, Mitrakos $\mathrm{A}^{1,3}$, Lazaros $\mathrm{L}^{1}$, Pantou $\mathrm{A}^{1}$, Mavrou A ${ }^{1}$, Tzetis $\mathrm{M}^{3}$, Manola $\mathrm{KN}^{2}$ \\ *Corresponding Author: Dr. Sophia Zachaki, Genesis Genoma Lab, Kifisias Avenue 302, Chalandri, \\ 15232, Athens, Greece. Tel.: +30-210-6803130. Fax:+30-210-6894778. E-mail: szachaki@genlab.gr
}

\begin{abstract}
A novel de novo paracentric inversion of the long arm of chromosome 20 [inv(20)(q13.1q13.3)], detected by conventional karyotyping in a 14-year-old boy with mental retardation is described. Further investigation by array comparative genomic hybridization (aCGH) revealed that the $20 \mathrm{q}$ inversion was not accompanied by microdeletions/microduplications containing disease-associated genes near or at the breakpoints. Two deletions at chromosomal regions $11 \mathrm{q} 14.3 \mathrm{q} 21$ and $20 \mathrm{q} 12$ of 4.5 and $1.97 \mathrm{Mb}$ size, respectively, containing important online Mendelian inheritance in man (OMIM) genes, were detected. The $4.5 \mathrm{Mb} 11 \mathrm{q} 14.3 \mathrm{q} 21$ microdeletion was contained within a region that is involved, in most of the reported cases, with the interstitial $11 \mathrm{q}$ deletion and may be related to the mental retardation and developmental delay present in the patient. On the other hand, the published data about the $20 \mathrm{q} 12$ microdeletion are very few and it is not possible to correlate this finding with our patient's phenotype. This case report contributes to the description of a new chromosomal entity, not previously reported, and is therefore important, especially in prenatal diagnosis and management of patients. Array comparative genomic hybridization has proven a useful technique for detecting submicroscopic re-
\end{abstract}

\footnotetext{
${ }^{1}$ Genesis Genoma Lab, Genetic Diagnosis, Clinical Genetics \& Research, Athens, Greece;

${ }^{2}$ Laboratory of Health Physics, Radiobiology \& Cytogenetics, NCSR "Demokritos", Athens, Greece;

${ }^{3}$ Department of Medical Genetics, Medical School, University of Athens, Greece;
}

arrangements and should be offered prenatally, especially in cases of de novo karyotypically balanced chromosomal inversions or translocations in order to unveil other unbalanced chromosomal abnormalities such as deletions and amplifications.

Keywords: Array comparative genomic hybridization (aCGH); G-banding; Microdeletion; Microduplication; Paracentric inversion (PAI).

\section{INTRODUCTION}

Paracentric inversion (PAI) is a common rearrangement that involves two breaks within the same chromosome arm, followed by the reinsertion of the chromosome segment into its original location after a $180^{\circ}$ rotation. The incidence of PAIs in the general population has not been clearly established but seems to range from 0.1 to $0.5 \%[1,2]$. Although PAIs are generally considered to be harmless with no phenotypic consequences, an abnormal phenotype has been described in cases where microduplications/microdeletions occur, or critical genes have been interrupted at the breakpoints [3-5].

Paracentric inversions can only be detected by conventional cytogenetic analysis. However, submicroscopic chromosomal imbalances at breakpoint junctions of the inverted segment can be unveiled using molecular cytogenetic techniques, such as array comparative genomic hybridization (aCGH).

In this report we present a novel de novo PAI on the long arm of chromosome $20[\operatorname{inv}(20)(q 13.1 q 13.3)]$, detected by conventional karyotyping in a 14-year-old boy with mental retardation, which was further investigated for other submicroscopic imbalances using aCGH. 


\section{CASE REPORT}

The patient is a 14-year-old boy with intellectual disability who was diagnosed prenatally with a paracentric inversion of the long arm of chromosome 20 (20q). Chorionic villus sampling was performed during the 12 th week of gestation due to advanced maternal age ( 35 years old). The karyotype of the fetus was described as 46,XY,inv(20) (q13.1q13.3). Parental karyotypic analysis was not performed at that time.

At birth, his weight was $2900 \mathrm{~g}$ and he had an apparently normal phenotype. At 9 months of age, the parents noticed hypotonia, head support delay and inability to situp by the age of 9 months. At approximately 17 months of age, he presented with developmental delay, dysmorphic features, psychomotor retardation and Duane syndrome anomalies. Brain magnetic resonance imaging (MRI) revealed cerebellar hypoplasia. He began occupational therapy and speech therapy at 4 years of age.

Presently, he does not have complete control and coordination of his body, especially for delicate movements. He has normal physical and sexual development, but he has problems in perception, speech expression and in self-care, although he shows gradual improvement. The patient does not show evidence of autism, stereotypy and automatic repetition of vocalizations such as echolalia. He is a happy and sensitive child who often cries but easily becomes happy. He attends a special school, is social, cooperative, seeks friendships and likes playing with other children.

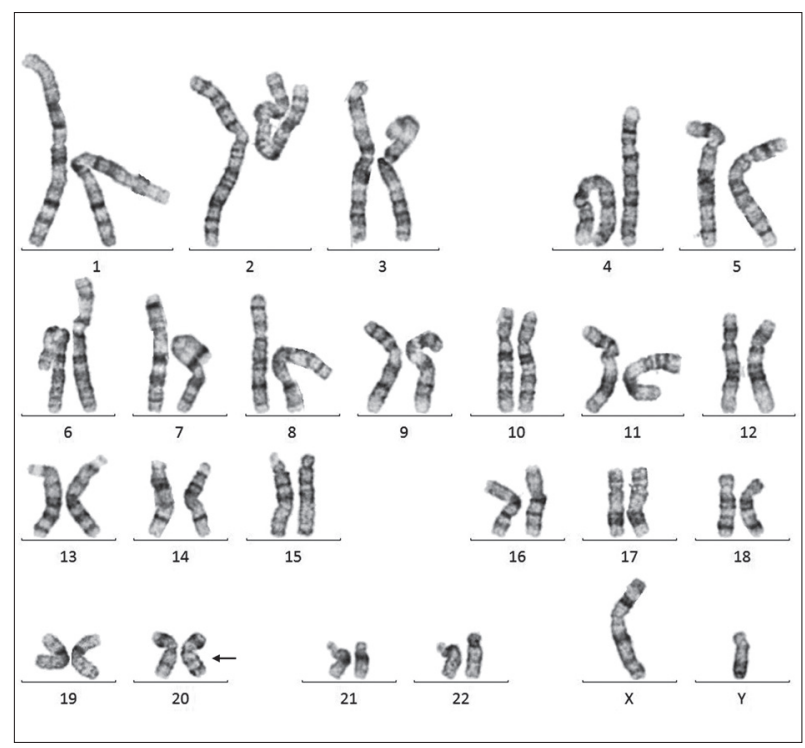

Figure 1. Patient's karyotype [46,XY,inv(20)(q13.1q13.3)] detected by a conventional cytogenetic G-banding technique.

\section{METHODS AND RESULTS}

Cytogenetic analysis of the boy and his parents was performed on G-banded chromosome preparations at high resolution level (>550 bphs) from PHA (phytohemagglutinin)-stimulated peripheral blood lymphocytes. Imaging and karyotyping were achieved via microscopy and computer imaging techniques. For each individual, 25 metaphases were fully analyzed and karyotypes were described according to the International System for Human Cytogenetic Nomenclature (ISCN) 2016 [6]. Karyotypic analysis showed that the boy was a carrier of a PAI of chromosome 20, with breakpoints at q13.1 and q13.3 chromosomal regions in all metaphases analyzed [46,XY, inv(20) (q13.1q13.3)] (Figure 1), confirming the prenatal karyotype. Karyotypes of both parents were normal indicating that inv(20) was a de novo chromosomal abnormality in the child. Written informed consent was obtained from the patient's mother for publication of this case report and accompanying images.

Fluorescent in situ hybridization (FISH) performed on peripheral blood of the boy using whole chromosome paint for chromosome 20 (Vysis, Abbott Laboratories, Lake Bluff, IL, USA) revealed a normal hybridization pattern. Therefore, the karyotype was defined as 46,XY,inv(20) (q13.1q13.3).ishinv(20)(q13.1q13.3) (wcp20+) de novo.

Molecular karyotyping was also performed in order to identify possible submicroscopic unbalanced chromosomal aberrations not detectable by G-banded chromosomal analysis. The G3 4x180k CGH+SNP (single nucleotide polymorphism) microarray platform with an

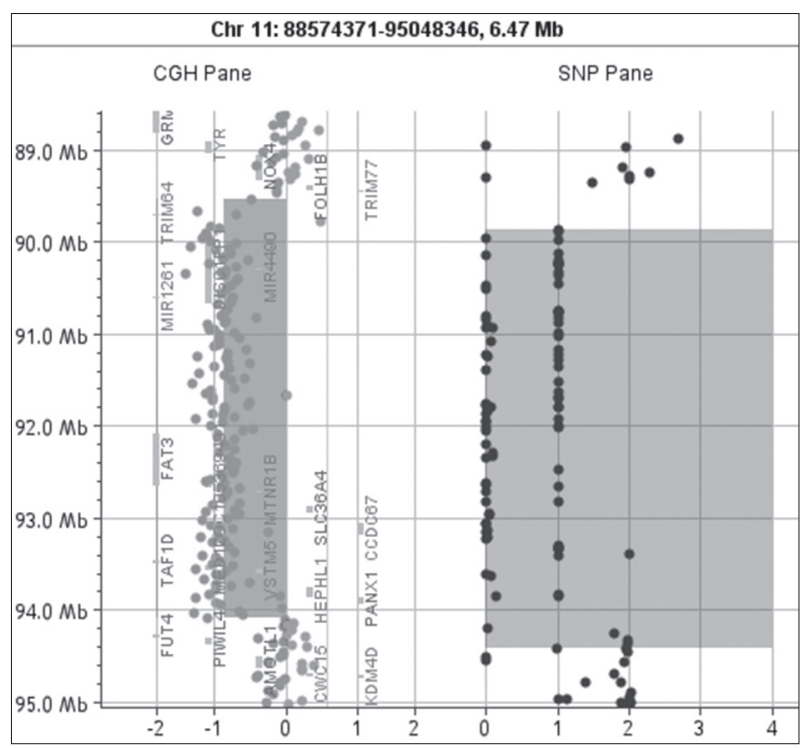

Figure 2. A diagram of the $4.5 \mathrm{Mb} 11 \mathrm{q}$ deletion (89545468-94077250). 
average probe spacing of $13 \mathrm{~kb}$ (Agilent Technologies, Santa Clara, CA, USA) was used. Samples were processed according to manufacturer's instructions and CytoGenomics 4.1 software (Agilent Technologies) was used for feature extraction and visualization of the resulting data. For annotation of genes in the deleted or duplicated genomic segments the University of California Santa Cruz (UCSC) Genome Browser (http://genome.ucsc.edu/), the Database of Genomic Variants (http://projects.tcag.ca/variation/; human genome build 19) and DECIPHER (https://decipher. sanger.ac.uk/) databases, were used.

Array comparative genome hybridization revealed a $100 \mathrm{~kb}$ microdeletion in the inverted segment at the 20q13.12 region, which is considered a copy number polymorphism. In addition, an interstitial deletion of $1.97 \mathrm{Mb}$ at the chromosomal region 20q12 (20:38157428-40128669) was revealed, distal from the inverted segment that included 11 genes (Table 1), among which is the $M A F B$ OMIM morbid gene. Interestingly, another deletion of 4.5 $\mathrm{Mb}$ was detected at chromosomal region 11q14.3-11q21 (11:89545468-94077250, hg19) containing 36 genes of uncertain clinical significance (Figure 2). Detected relevant microduplications and microdeletions are presented in Table 1.

\section{DISCUSSION}

A novel PAI of the long arm of chromosome 20 $[\operatorname{inv}(20)(q 13.1 q 13.3)]$ is described in a patient with mental retardation. To the best of our knowledge, this case is the first reported PAI of $20 \mathrm{q}$ in the literature. Although the great majority of PAIs are familial (about 90.0\%) [7], conventional cytogenetic analysis of the patient's parents revealed the de novo origin of this abnormality.

In general, PAIs are balanced and have no phenotypic consequences for the carriers. However, in cases where microdeletions/microduplications occur at the breakpoints, an abnormal phenotype could result [3-5]. In our patient, aCGH showed a $100 \mathrm{~kb}$ microdeletion in the inverted segment at the 20q13.12 region-considered polymorphic CNP (copy number polymorphism), since it is reported in the database of genomic variance (DGV) and has not been associated with abnormal phenotypic features in carriers. Two other microdeletions at chromosomal regions $20 \mathrm{q} 12$ and $11 \mathrm{q} 14.3 \mathrm{q} 21$, which were also found in our patient, were investigated for genes that could have contributed to the proband's phenotype.

Constitutional deletions concerning larger segments of the long arm of chromosome 20 are very rare, with only eight cases reported so far [8-13], containing genes that may be responsible for the development of the heart and the brain. The 20q12 (1.97 Mb) microdeletion found in our proband contains one important OMIM morbid gene, $M A F B$, missense mutations of which have been reported to be responsible for autosomal dominant multicentric carpotarsal osteolysis (MCO) $[14,15]$. Furthermore, loss of MAFB function due to mutations or whole gene deletion, has been reported in the frame of Duane retraction syndrome (DRS) with or without deafness [15]. However, these cases are actually different from our proband due to lack of most of the phenotypic characteristics of the $\mathrm{MCO}$ and DRS syndromes. On the other hand, one case carrying a 20q12 deletion of $2.49 \mathrm{Mb}$ has been published in DECIPHER (patient id: 267065). This patient carries a deletion containing 17 genes, including the $M A F B$ gene. The child's phenotype has behavioral abnormality, delayed speech and language development, intellectual disability and sleep disturbance.

The majority of 11q deletions are terminal and has been associated with a genetic disorder known as Jacobsen syndrome [16]. Interstitial 11q deletions are rare and only 35 cases have so far been described in the literature. They are highly heterogeneous in size and position and present with variable phenotypic characteristics, with most

Table 1. Relevant array comparative genomic hybridization findings, genes content and characterization.

\begin{tabular}{|l|c|c|l|l|}
\hline $\begin{array}{l}\text { Chromosomal } \\
\text { Region/Size }\end{array}$ & $\begin{array}{c}\text { Start } \\
\text { (hg19) }\end{array}$ & $\begin{array}{c}\text { End } \\
\text { (hg19) }\end{array}$ & \multicolumn{1}{|c|}{ Genes } & Characterization \\
\hline $\begin{array}{l}\text { del 11q14.3-q21 } \\
(4.5 \mathrm{Mb})\end{array}$ & 89545468 & 94077250 & $\begin{array}{l}\text { TRIM53AP, TRIM64B, TRIM49D2, TRIM49D1, TRIM64, } \\
\text { TRIM49C, UBTFL1, NAALAD2, CHORDC1, DISC1FP1, } \\
\text { MIR4490, MIR1261, FAT3, LOC105369431, MTNR1B, } \\
\text { SLC36A4, CCDC67, SMCO4, CEP295, SCARNA9, } \\
\text { SNORA25, SNORA32, SNORD6, SNORA1, SNORA8, } \\
\text { SNORD5, SNORA18, MIR1304, SNORA40, TAF1D, } \\
\text { C11orf54, MED17, VSTM5, HEPHL1, PANX1, IZUMO1R }\end{array}$ & $\begin{array}{l}\text { uncertain clinical } \\
\text { significance }\end{array}$ \\
\hline $\begin{array}{l}\text { del 20q12 } \\
(1.97 \mathrm{Mb})\end{array}$ & 38157428 & 40128669 & $\begin{array}{l}\text { LINC01370, MAFB, LOC100128988, TOP1, PLCG1-AS1, } \\
\text { PLCG1, MIR6871, ZHX3, LPIN3, EMILIN3, CHD6 }\end{array}$ & $\begin{array}{l}\text { uncertain clinical } \\
\text { significance }\end{array}$ \\
\hline $\begin{array}{l}\text { del 20q13.12 } \\
(100 \mathrm{~kb})\end{array}$ & 43916414 & 44016199 & MATN4, RBPJL, SDC4, SYS1, SYS1-DBNDD2, TP53TG5 & $\begin{array}{l}\text { copy number } \\
\text { polymorphism }\end{array}$ \\
\hline
\end{tabular}


cases exhibiting mild to severe mental retardation, and as in our proband, developmental delay. However, in only six of the reported cases, the breakpoints of the deleted segment have been identified by molecular cytogenetic techniques $[17,18]$, thus, it is hard to define the distinct genotype/ phenotype correlation of the 11q deletion. The common interstitial $11 \mathrm{q}$ deleted region contains the 4.5 $\mathrm{Mb} 11 \mathrm{q} 14.3-11 \mathrm{q} 21$ microdeletion was also found in our proband [18]. The genes contained in the 11q14.3-11q21 microdeleted region in our proband are 36 and are characterized as genes with uncertain clinical significance. The most important one is $M E D 17$, for which many specific missense mutations have been reported in individuals with mental retardation, psychomotor delay and cerebellar atrophy, phenotypic features shared with our proband [19,20]. Apart from the reported MED17 mutation, one patient carrying a $6.38 \mathrm{Mb}$ deletion containing the MED17 gene has also been reported in the DECIPHER database (patient id: 267158). This patient has tall stature, macrocephaly, autism, delayed speech and language development, echolalia and stereotypy. Therefore, it is possible that the $11 \mathrm{q} 14.3-11 \mathrm{q} 21$ microdeletion may contribute to our patient's phenotype.

In conclusion, this is the first report of a patient with an apparently balanced de novo 20q PAI, which after aCGH testing was not accompanied by microdeletions/ microduplications containing disease-associated genes near or at the breakpoints, indicating that it is probably not associated with the proband's abnormal phenotype. However, based on published data, the 11q14.3-11q21 micro-deletion detected by aCGH may be related to the mental retardation and developmental delay of the patient. As the published data about the $20 \mathrm{q} 12$ microdeletion are very few, it is not possible to correlate this finding with our patient's phenotype.

This case report describes a new chromosomal entity with an important contribution to the management of prenatal diagnosis with similar findings. Array comparative genome hybridization is proven to be a useful technique for detecting unbalanced submicroscopic rearrangements with the exception of balanced chromosomal rearrangements and mosaicism of less than $20.0 \%$. It could be offered prenatally or postnatally, in combination with conventional cytogenetic techniques, especially in cases of de novo karyotypically balanced chromosomal inversions or translocations or normal karyotype where an abnormal phenotype or mental retardation exists.

\section{ACKNOWLEDGMENTS}

The authors would like to thank the parents of the child for their permission to participate in the present study and Professor Emmanuel Kanavakis (Genesis Genoma Lab, Genetic Diagnosis, Clinical Genetics \& Research, Athens, Greece) for his contribution to genetic counseling.

Declaration of Interest. The authors report no conflicts of interest. The authors alone are responsible for the content and writing of this article.

\section{REFERENCES}

1. Fryns JP, van den Berghe H. Paracentric inversion in man: Personal experience and review of the literature. Hum Genet. 1980; 54(3): 413-416.

2. Hook EB, Schreinemachers DM, Willey AM, Cross PK. Inherited structural cytogenetic abnormalities detected incidentally in fetuses diagnosed prenatally: Frequency, parental-age associations, sex-ratio trends and comparisons with rates of mutants. Am J Hum Genet. 1984; 36(2): 422-443.

3. Madan K. Paracentric inversions: A review. Hum Genet. 1995; 96(5): 503-515.

4. Greger V, Knoll JH, Wagstaff J,Woolf E, Lieske P, Glatt $\mathrm{H}$, et al. Angelman syndrome associated with an inversion of chromosome 15q11.2q24.3. Am J Med Genet. 1997; 60(3): 574-580.

5. Saito-Ohara F, Fukuda Y, Ito M, Agarwala KL, Hayashi M, Matsuo M, et al. The Xq22 inversion breakpoint interrupted a novel Ras-like GTPase gene in a patient with Duchenne muscular dystrophy and profound mental retardation. Am J Hum Genet. 2002; 71(3): 637-645.

6. McGowan-Jordan J, Simons A, Schmid M, Editors. ISCN 2016: An International System for Human Cytogenomic Nomenclature, 2016 ed. Basel, Switzerland: S. Karger AG, 2016.

7. Vialard F, Delanete A, Clement P, Simon-Bouy B, Aubriot FX, Selva J. Sperm chromosome analysis in two cases of paracentric inversion. Fertil Steril. 2007; 87(2): 418.e1-e5.

8. Aldred MA, Aftimos S, Hall C, Waters KS, Thakker $\mathrm{RV}$, Trembath RC, et al. Constitutional deletion of chromosome $20 \mathrm{q}$ in two patients affected with albright hereditary osteodystrophy. Am J Med Genet. 2002; 113(4): 167-172. 
9. Fraisse J, Bertheas MF, Frere F, Lauras B, Rolland MO, Brizard CP. Partial monosomy 20q: A new syndrome. Regional assignment of the adenosine deaminase (ADA) locus on 20q132. Ann Genet. 1981; 24(22): 216-219.

10. Genevieve D, Sanlaville D, Faivre L, Kottler ML, Jambou M, Gosset P, et al. Paternal deletion of the GNAS imprinted locus (including Gnasxl) in two girls presenting with severe pre- and post-natal growth retardation and intractable feeding difficulties. Eur J Hum Genet. 2005; 13(9): 1033-1039.

11. Petersen MB, Tranebjaerg L, Tommerup N, Nygaard $\mathrm{P}$, Edwards H. New assignment of the adenosine deaminase gene locus to chromosome20q13.11 by study of a patient with interstitial deletion $20 \mathrm{q}$. J Med Genet. 1987; 24(2): 93-96.

12. Shabtai F, Ben-Sasson E, Arieli S, Grinblat J. Chromosome 20 long arm deletion in an elderly malformed man. J Med Genet. 1993; 30(2): 171-173.

13. Lin Y, Chen C, Chen T, Hsu C, Chou S, Chien S. Prenatal diagnosis of a de novo interstitial deletion of chromosome 20q12 in a fetus with complex congenital heart defects, corpus callosum agenesis and intrauterine growth restriction. Taiwan J Obstet Gynecol. 2011; 50(4): 528-530.

14. Zankl A, Duncan E, Leo P, Clark G, Glazov E, Addor $\mathrm{M}$, et al. Multicentric carpotarsal osteolysis is caused by mutations clustering in the amino-terminal transcriptional activation domain of MAFB. Am J Hum Genet. 2012; 90(3): 494-501.
15. Park J, Tischfield MA, Nugent AA, Cheng L, Di Gioia SA, Chan WM, et al. Loss of MAFB function in humans and mice causes Duane syndrome, aberrant extraocular muscle innervation, and inner-ear defect. Am J Hum Genet. 2016; 98(6): 1220-1227.

16. Grossfeld PD, Mattina T, Lai Z, Favier R, Jones KL, Cotter F, et al. The 11q terminal deletion disorder: A prospective study of 110 cases. Am J Med Genet A. 2004; 129A(1): 51-61.

17. Liu N, Yan J, Chen X, Song J, Wang B, Yao Y. Prenatal diagnosis of a de novo interstitial deletion of $11 \mathrm{q}(11 \mathrm{q} 22.3 \rightarrow \mathrm{q} 23.3)$ associated with abnormal ultrasound findings by array comparative genomic hybridization. Mol Cytogenet. 2014; 25(7): 62.

18. Papoulidis I, Paspaliaris V, Siomou E, Orru S, Murru $\mathrm{R}$, Sifakis $\mathrm{S}$, et al. Interstitial deletion at 11q14.211q22.1 may cause severe learning difficulties, mental retardation and mild heart defects in 13-year old male. Mol Cytogenet. 2015; 8: 71-78.

19. Kaufmann R, Straussberg R, Mandel H, Fattal-Valevski A, Ben-Zeev B, Naamati A, et al. Infantile cerebral and cerebellar atrophy is associated with a mutation in the MED17 subunit of the transcription preinitiation mediator complex. Am J Hum Genet. 2010; 87(5): 667-670.

20. Hirabayashi S, Saitsu H, Matsumoto N. Distinct but milder phenotypes with choreiform movements in siblings with compound heterozygous mutations in the transcription preinitiation mediator complex subunit 17 (MED17). Brain Dev. 2016; 38(1): 118-123. 